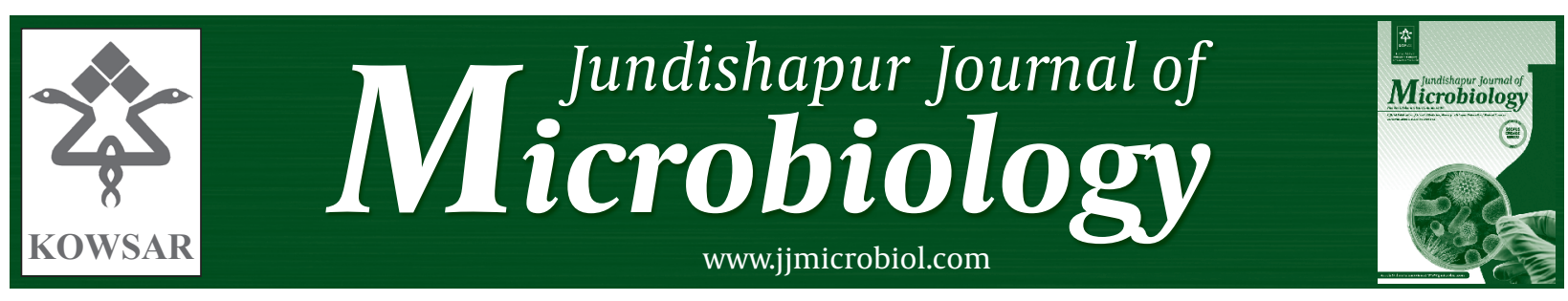

\title{
Trivalent Arsenic Tolerance and Accumulation in Two Facultative Marine Fungi
}

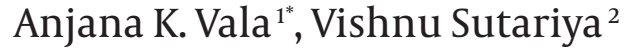 \\ ${ }^{1}$ Department of Physics, Bhavnagar University, Bhavnagar, India \\ ${ }^{2}$ Shree Dhanvantary Pharmaceutical and Research Institute, Kim, India
}

\begin{tabular}{l}
\hline A R T I C I E I N F O \\
\hline Article type: \\
Original Article \\
\hline Article history: \\
Received: 03 Nov 2011 \\
Revised: 08 Jan 2012 \\
Accepted: 22 Feb 2012
\end{tabular}

Keywords:

Fungi

Arsenic

Tolerance

Accumulation

Bioremediation

\begin{abstract}
A B S T R A C T
Background: Facultative marine fungi could potentially be arsenic tolerant and may be able to remove this highly poisonous metal from the environment.

objectives: The objective of this work was to explore the degree of tolerance and removal efficiency of two facultative marine fungi.

Materials and Methods: Facultative marine fungi Aspergillus flavus and Rhizopus spp. were exposed to $25 \mathrm{mg} / \mathrm{L}$ and $50 \mathrm{mg} / \mathrm{L}$ sodium arsenite (As (III)). Tolerance of these species to the test concentrations was assessed by studying their biomass accumulation. Accumulation of arsenic by the fungal biomass was also evaluated.

Results: Our study revealed that both A. flavus and Rhizopus sp. exhibited tolerance towards the test concentrations of arsenic. Both of the test fungi also exhibited arsenic accumulation. Rhizopus sp. was found to be a slightly better potential accumulator.

Conclusions: This study reveals that the test fungi can be harnessed as bioremediation agents for arsenic contaminated sites.
\end{abstract}

Published by Kowsar Corp, 2012. cc 3.0.

\section{- Implication for health policy/practice/research/medical education:}

The results displayed potentials of marine derived fungi for arsenic removal. This work can be a baseline information for designing bioremediation strategies.

Please cite this paper as:

Vala AK, Sutariya V. Trivalent Arsenic Tolerance and Accumulation in Two Facultative Marine Fungi. Jundishapur J Microbiol. 2012;5(4):542-5. DOI: $10.5812 / j j m .3383$

\section{Background}

Arsenic, a highly toxic metalloid, is present in the environment due to anthropogenic and natural processes. Its mobility and bioavailability is influenced by abiotic as well as biotic (especially microorganisms) factors $(1,2)$. Consequences of arsenic exposure range from; minor disorders to permanent severe damage and death (3). Arsenic contamination has become a major public health concern in countries such as; India, China, Argentina, Canada and the USA $(4,5)$. Conventional technologies for arsenic removal are not particularly cost effective and suffer from one or other limitation (6-9).

Bioremediation using microbes could be a potential strategy for the removal of such toxicants, as fungi have great growth capacity, developed by virtue of mycelia branching. They have the potential to produce a large number of enzymes and they are also good accumulators of various metals, which can be screened for promising bioremediation agents. Exploration of the marine habitat for facultative marine fungi is all the more crucial, as it may lead to the screening of fungal strains with superior

\footnotetext{
* Corresponding author: Anjana K. Vala, Department of Physics, Bhavnagar University, Bhavnagar, India. Tel: +91-2782422650, Fax:+91-2782513943,

E-mail:anjana_vala@yahoo.co.in

DOI:10.5812/jjm.3383

(C) 2012 Ahvaz Jundishapur University of Medical Sciences; Published by Kowsar Corp.

This is an Open Access article distributed under the terms of the Creative Commons Attribution License (http://creativecommons.org/licenses/by/3.0), which permits unrestricted use, distribution, and reproduction in any medium, provided the original work is properly cited.
} 
potentials due to their ability to grow under extreme conditions such as; high salinity and $\mathrm{pH}$ which may aid in the treatment of industrial effluent.

\section{Objectives}

The present work focuses on an examination of facultative marine fungal isolates Aspergillus flavus and Rhizopus sp. for tolerance and accumulation of trivalent arsenic (As (III)), one of the most hazardous metal toxicants, and thus, to explore their potentiality for use as bioremediation agents of arsenic contaminated sites. A. flavus (mitosporic Trichomaceae) and Rhizopus sp. (Mucoraceae) are the molds commonly distributed in the coastal areas of Bhavnagar. Typically, they play a saprophytic role, however, A. flavus may also be a human pathogen as it can produce aflatoxin (10).

\section{Materials and Methods}

\subsection{Organisms}

In the present work, organisms selected were facultative marine fungi A. flavus and Rhizopus sp. The test isolates were extracted from the waters of the Bhavnagar coast (Lat. $21^{\circ} 45^{\prime} \mathrm{N}$ and Long. $72^{\circ} .14^{\prime} \mathrm{E}$ ), Gulf of Cambay, West Coast of India. The isolates were grown and maintained on potato dextrose agar (PDA) (HiMedia, India) medium (11) and stored at $4^{\circ} \mathrm{C}$ until required. The medium was prepared in aged seawater and distilled water at a ratio of $3: 1$ (12).

\subsection{Medium and Biomass Accumulation}

One milliliter inoculum (approximately $10^{6} \mathrm{spores} / \mathrm{ml}$ ) was inoculated in $250 \mathrm{ml}$ PDA medium containing different concentrations of As (III), i.e. 25 and $50 \mathrm{mg} / \mathrm{L}$, as sodium arsenite (13). Spore suspensions were prepared by harvesting spores from an agar slant after $72 \mathrm{~h}$. One set of medium without As (III) was kept as a control. The medium was prepared in aged seawater and distilled water at a ratio of 3:1. Each set was triplicated. (The values reported are an average of the results of the duplicate sets.) The respective flasks were incubated at room temperature for nine days. One flask from each set was removed at three day intervals (i.e. day three, six and nine) and the effect of the arsenic on the biomass (and in this way tolerance to As) was recorded in terms of gram dry weight. To achieve this, the fungal pellets were removed from each medium flask and kept in an oven at $80^{\circ} \mathrm{C}$ for $5 \mathrm{~h}$ and the dry weight was measured.

\subsection{Determination of Metal Content}

Content of the As in the fungal biomass was estimated using a hydride generation atomic absorption spectrophotometer, Japan (Shimadzu 6300). The biomass samples were digested with nitric acid (14) and the content was expressed as $\mathrm{mg} / \mathrm{g}$ biomass (13).

\section{Results}

The consequences of exposing A. flavus and Rhizopus sp. to a trivalent form of arsenic were noted in terms of biomass accumulation (g dry wt.) and the As content (mg/g) which was found in the fungus. Both of the test fungi exhibited luxuriant growth in all flasks (controls as well as those containing As (III)). Figure 1a and 1b show biomass accumulation by the test fungi over a period of 9 days in different conditions. There was a rise in biomass accumulation in all of the cases, as is evident in the figures. When $A$. flavus was exposed to 25 and $50 \mathrm{mg} / \mathrm{L}$ of As (III), invariably a higher biomass was recorded in the controls (Figure 1a). However, the biomass accumulation was largely unaffected by exposure to As (III) as there is no marked variation in the values recorded for the different conditions.

Biomass accumulation was almost the same in both cases of the arsenic test concentrations. This is a significant affir-
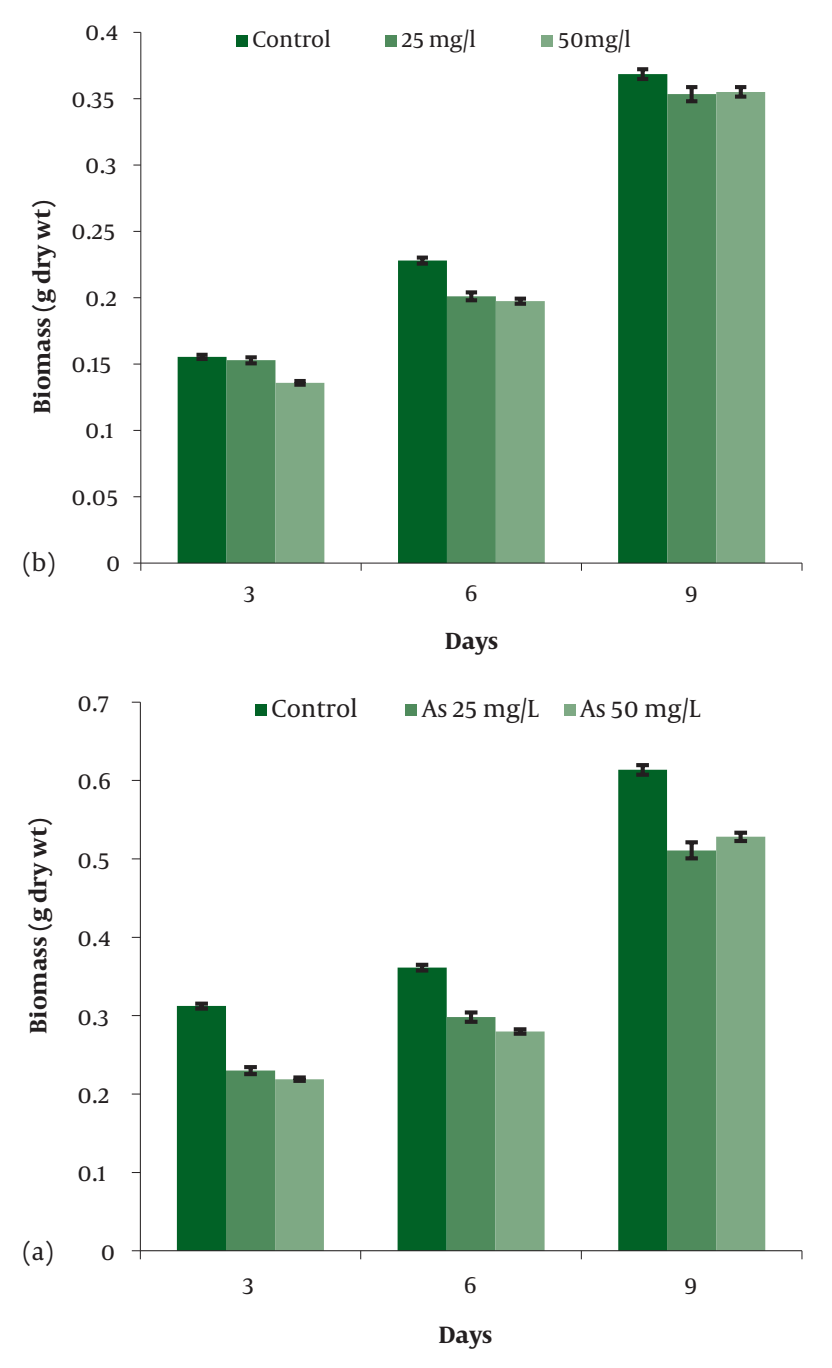

Figure 1. Biomass Accumulation (g/dry weight) by (a) Aspergillus flavus and (b) Rhizopus sp. In Absence and Presence of 25 and $50 \mathrm{mg} / \mathrm{l} \mathrm{As}$ (III) 
mation for the test fungus' future use in bioremediation. Upon exposure to 25 and $50 \mathrm{mg} / \mathrm{L}$ As (III), compared to the control, the biomass changes for Rhizopus sp. were not significant. When Rhizopus sp. was examined for 25 and 50 $\mathrm{mg} / \mathrm{L}$ As (III), it exhibited luxuriant growth in the control flasks as well as in all flasks containing As (III). Biomass accumulation did not vary significantly either, thus, indicating tolerance of Rhizopus sp. to As (III) (Figure 1b). Our study revealed that both A. flavus and Rhizopus sp. exhibited tolerance towards test concentrations of arsenic. Thus, both test fungi essentially fulfilled the primary criterion for their application as bioremediation agents, although A. flavus was found to be slightly more sensitive than Rhizopus sp.

Differences in species sensitivity had been reported earlier $(15,16)$. The atomic absorption spectrophotometry revealed the presence of arsenic content in the test fungi grown in medium containing 25 as well as $50 \mathrm{mg} / \mathrm{L} \mathrm{As}$ (III) (Figure $2 a$ and $2 b$ ). In the control samples As was not
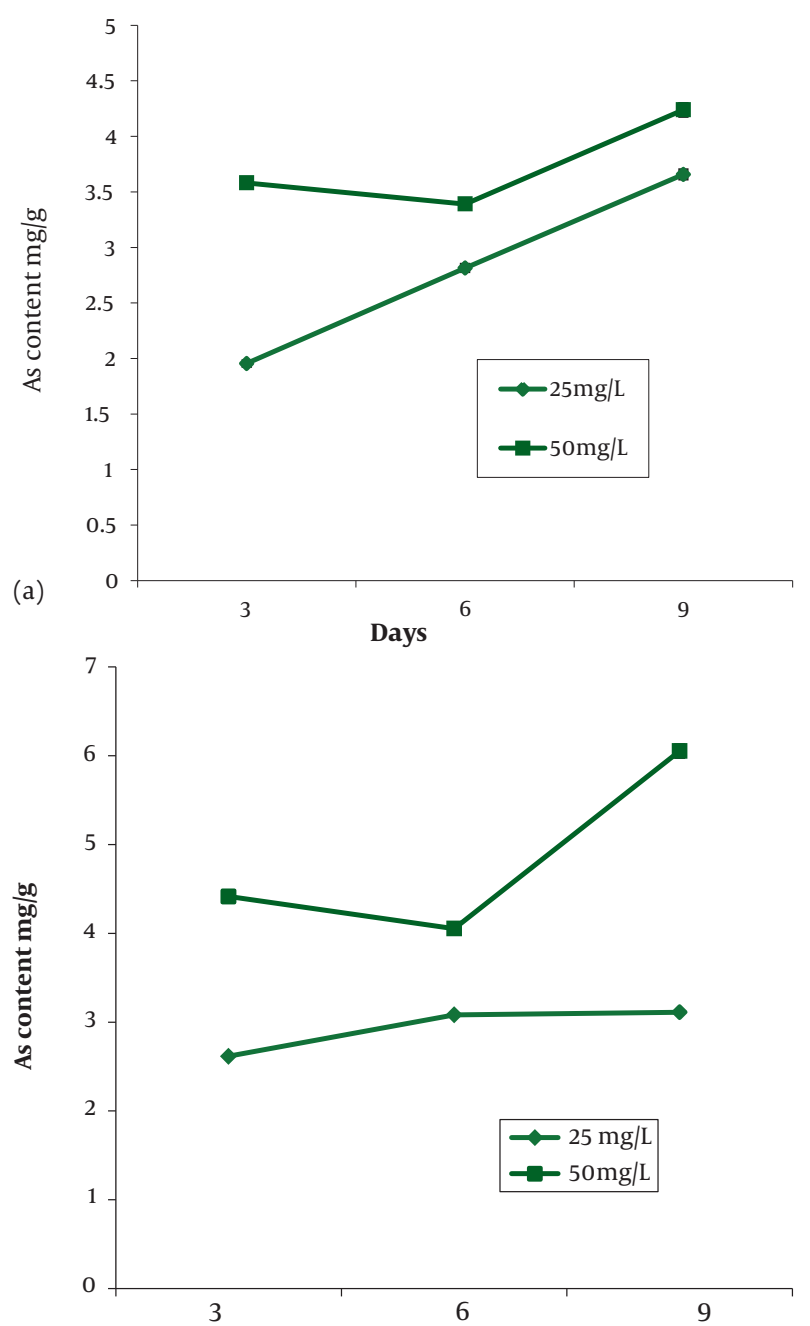

(b)

Days

Figure 2. Biomass Accumulation (g/dry weight) by (a) Aspergillus flavus and (b) Rhizopus sp. in Absence and Presence of 25 and $50 \mathrm{mg} / \mathrm{L}$ As (III) detected. In the case of A. flavus, the arsenic content (mg/g dry weight) in the test fungus extracted from the pellets removed from the medium containing $25 \mathrm{mg} / \mathrm{L}$ As (III) on day three, six and nine, respectively, indicated an invariable increase in accumulation over time. In the pellets removed from the medium containing $50 \mathrm{mg} / \mathrm{L}$ As (III), the arsenic content recorded on day three, six and nine, respectively, showed a slight decrease in accumulation on day six but it reached the highest point on day nine (Figure 2a).

Content in the Rhizopus sp., when exposed to $25 \mathrm{mg} / \mathrm{L}$ As (III), was found to increase on day three, six and nine, respectively, there was also an increase in As accumulation over time. When exposed to $50 \mathrm{mg} / \mathrm{L}$ As (III) for nine days, Rhizopus sp. showed a slight decrease in accumulation on day six and again reached the highest point on day nine (Figure 2b).

\section{Discussion}

Both of the test fungi exhibited similar patterns of accumulation when exposed to different As concentrations. Rhizopus sp. was found to be a more potential accumulator than A. flavus. In both test fungi, the higher As content was invariably recorded in the cases exposed to 50 $\mathrm{mg} / \mathrm{L}$ As (III) compared to the samples of $25 \mathrm{mg} / \mathrm{L}$. This is in agreement with Vala (13) and Vala et al. (17). Similar observations for chromium have also been reported by Say et al. (18), suggesting higher complexation rates between the metal and metal complexing group on the biomass in the presence of higher concentrations of the metal. Higher arsenic removal rates from mediums supplied with higher arsenic concentrations was also observed by Cernansky et al. (19).

Arsenic removal by modified A. niger biomass has been reported by Pokhrel and Viraraghavan (20) where the modified biomass removed $75 \%$ of the As (III) when supplied with a $100 \mu \mathrm{g} / \mathrm{L}$ As concentration. Loukidou et al.(21) reported a higher removal ability by chemically modified Penicillium chrysogenum than with an unmodified biomass. Dursun et al. (22) have reported the application of growing cultures for the bioaccumulation of heavy metals. In the present work, the growing cultures have also exhibited promising metal removal efficiency.

This study is a positive indication for further exploration of the possibilities for using the test fungi as a source of bioremediation. Studies on the effects of higher As concentrations and other parameters on the ability of the test fungi to remove metals are currently in progress in our laboratory. Facultative marine fungi A. flavus and Rhizopus sp., exhibited tolerance towards arsenic and both of the test fungi also showed arsenic removal potential. Further explorations are required, however, the test fungi appear to be promising bioremediation agents. 


\section{Acknowledgements}

AKV acknowledges the Department of Science and Technology (DST), Govt. of India, New Delhi, for the financial support in the form of FTPYS project (No. SR/FT/L99/2006). Thanks are also due to the Council of Scientific and Industrial Research, Govt. of India, New Delhi.

\section{Financial Disclosure}

The authors report no conflicts of interest. The authors alone are responsible for the content and writing of the paper.

\section{Funding Support}

The work was funded by the Department of Science and Technology (DST), Govt. of India, New Delhi (No. SR/FT/L 99/2006).

\section{References}

1. Gadd GM. Tansley Review No. 47. Interactions of fungi with toxic metals. New Phytol.1993:25-60.

2. Sadiq M. Arsenic chemistry in soils: An overview of thermodynamic predictions and field observations. Water Air Soil Pollut. 1997;93 (1):117-36.

3. Benramdane L, Bressolle F, Vallon JJ. Arsenic speciation in humans and food products: a review. J Chromatogr Sci. 1999;37 (9):330-44.

4. Gehle K, Substances USAfT, Registry D. Arsenic Toxicity. Atlanta, GA: Agency for Toxic Substances and Disease Registry; 2009.

5. World Health Organization. Environmental health criteria 224: arsenic and arsenic compounds. WHO,Geneva. 2001:1-108.

6. Chwirka J, Thompson BM, Stomp III JM. Removing arsenic from groundwater. J Am Water Works As. 2000;92 (3):79-88.

7. Clifford D, Sorg T. Removing dissolved inorganic contaminants from water. Environ Sci Technol. 1986;20 (11):1072-9.
8. Driehaus W, Seith R, Jekel M. Oxidation of arsenate(III) with manganese oxides in water treatment. Water Res. 1995;29 (1):297-305.

9. Wilkie JA, Hering JG. Rapid oxidation of geothermal arsenic (III) in streamwaters of the eastern Sierra Nevada. Environ Sci Technol. 1998;32 (5):657-62.

10. Klich MA. Aspergillus flavus: the major producer of aflatoxin. Mol Plant Pathol. 2007;8 (6):713-22.

11. Commonwealth Mycological Institute, Commonwealth Agriculf tural Bureaux. Plant Pathologist's Pocketbook.1968 .

12. Schlieper C. Research methods in marine biology. Seattle: Sidgwick \& Jackson; 1972.

13. Vala AK. Tolerance and removal of arsenic by a facultative marine fungus Aspergillus candidus. Bioresour Technol.2010;101 (7):2565-7.

14. Visoottiviseth P, Panviroj N. Selection of fungi capable of removing toxic arsenic compounds from liquid medium. Sci Asia. 2001;27:83-92.

15. Taboski MA, Rand TG, Piorko A. Lead and cadmium uptake in the marine fungi Corollospora lacera and Monodictys pelagica. FEMS Microbiol Ecol. 2005;53 (3):445-53.

16. Vala AK, Anand N, Bhatt PN, Joshi HV. Tolerance and accumulation of hexavalent chromium by two seaweed associated aspergilli. Mar Pollut Bull. 2004;48 (9-10):983-5.

17. Vala AK, Davariya V, Upadhyay R. An investigation on tolerance and accumulation of a facultative marine fungus Aspergillus flavus to pentavalent arsenic. J Ocean Univ China 2010;9 (1):65-7.

18. Say R, Yilmaz N, Denizli A. Removal of chromium (VI) ions from synthetic solutions by the fungus Penicillium purpurogenum. Eng Life Sci. 2004;4 (3):276-80.

19. Cernansky S, Kolencik M, Sevc J, Urik M, Hiller E. Fungal volatilization of trivalent and pentavalent arsenic under laboratory conditions. Bioresour Technol. 2009;100 (2):1037-40.

20. Pokhrel D, Viraraghavan T. Arsenic removal from an aqueous solution by a modified fungal biomass. Water Res. 2006;40 (3):549-52.

21. Loukidou MX, Matis KA, Zouboulis AI, Liakopoulou-Kyriakidou M. Removal of As (V) from wastewaters by chemically modified fungal biomass. Water Res. 2003;37 (18):4544-52.

22. Dursun A, Uslu G, Tepe O, Cuci Y, Eki HI. A comparative investigation on the bioaccumulation of heavy metal ions by growing Rhizopus arrhizus and Aspergillus niger. Biochem EngJ. 2003;15 (2):87-92. 